\title{
Modern trends in the development of agrarian sector
}

\author{
Farit Mukhametgaliev*, Ilgizar Gainutdinov, Marsel Khismatullin, Landysh Sitdikova and Farida Mukhametgalieva
}

Kazan State Agrarian University, Kazan, 420015, Russia

\begin{abstract}
The paper is relevant due to the need to ensure the sound functioning of all links constituting the economic agrarian sector by deepening research and elaborating recommendations to improve the economic mechanism for managing rural commodity producers in the face of fierce competition in the global food market. The paper proposes development trends and rationale for priority directions to nourish agrarian business and agricultural production. The paper is devoted to a comprehensive study of the current agrarian sector of the economy and the priority areas for sustainable agrarian business entities functioning in modern conditions of external and internal socio-political challenges. It provides a scientific rationale for the directions of state regulation of processes in rural areas. It defines the priority strategic directions for agrarian sector to flourish, improving the mechanisms of state regulation of agriculture. The theoretical provisions and practical recommendations proposed in the paper will solve the problem of sustainable growth in the production of competitive agricultural products, increasing the efficiency of state support, strengthening the economy of agricultural producers and ensuring the socio-economic development of rural areas.
\end{abstract}

\section{Introduction}

An important direction in achieving social and economic stability of the country is sustainable progressive development of the branches of the domestic economy. To a greater extent, this applies to the industries that provide the population with essential goods, promote national food security. Among the factors that have an important impact on the economic development, it is definitely necessary to highlight the identification of trends and the definition of priority strategically important directions for the development of the agrarian economic sector. The priority directions for the development of the agrarian sphere of life primarily involve a steady provision of increased growth rates of volumetric indicators in the industrial sectors of agricultural raw materials, achievement of financially stable activities of the entities comprising the agrarian business. Undoubtedly, the achievement of high performance indicators of agricultural production calls for the need to identify and address a whole range of current external and internal challenges, among which it is of paramount importance to create socio-political and organizational-economic prerequisites for successful functioning of agrarian entities adapted to market conditions, corresponding to the specific conditions for conducting production and financial activities, organizational and legal forms of business structures. All this undoubtedly reaffirms the relevance of choosing priority strategic directions to further promote the agrarian sector of the economy, which makes it necessary to continue exploring this issue, develop practical recommendations for the implementation of the policy of import substitution of food products and determine the development directions of certain areas of the agricultural business, followed by ensuring the national food security and building up the export potential of the national farming sector.

\section{Materials and Methods}

A theoretical and methodological toolkit rests on the interaction and complementarity of the fundamental provisions and concepts of economic theory. It was also made up by the publications of foreign and domestic agricultural economists on the topic, legislative acts of the Russian Federation on the regulation of agri-food policy, proceedings of international and all-Russian scientific and practical conferences dedicated to the development of agriculture. A general methodological basis is the system analysis. The extensive materials and the diverse content prompted the need to use, within the framework of system analysis, various approaches, methods and techniques of scientific research, including constructive, deterministic, retrospective, dynamic, and statistical. The methods used to reveal the trends in the development of agri-food policy and their functions include monographic, abstract-logical, calculationconstructive, economic and statistical, analogies. The official data of the Federal State Statistics Service of the Russian Federation, the Ministry of Agriculture of the Russian Federation, data resulting from the analysis and

\footnotetext{
* Corresponding author: fem59@mail.ru
} 
calculations performed by the authors were used as an information base.

\section{Results}

The level of farming development in modern conditions is determined by the final outputs achieved by one of the fundamental branches of agriculture - crop production. For many years, the value of goods produced by this industry has accounted for almost half of the value of the gross output for the entire agricultural sector and is largely involved in elaborating general indicators of the socio-economic development of rural areas. Food items produced in horticulture are of great importance for the development of other sectors of the national economy. Firstly, horticulture provides the population of the country with such essential foods as bread and bakery products, vegetable oil, sugar, potatoes, vegetables, melons and gourds, fruits and grapes. Secondly, crops, like grain and industrial crops, build a strong export potential of the farming industry. Thirdly, it acts as a driver for the development of animal husbandry as a supplier of grain fodder and feed necessary for obtaining animal products such as meat, milk, eggs, wool. Fourthly, plants such as fiber crops, oilseeds and partially cereals, fruits, vegetables and grapes, sugar beets are essential raw materials for processing industry enterprises [1,2].

The provision of the population with livestock products largely depends on the development of horticulture in general and grain production in particular, which is an important direction in ensuring the national food safety. This goal can be achieved only with the stable development of the entire agricultural industry that is mainly aimed at increasing the gross grain production and the economic efficiency of grain production through a sustainable production system.
Grain farming is a cornerstone of agricultural production and has a determinative effect on the development of all industries [3, 4].

The national food security agenda and the improvement of the well-being of the population can be implemented solely by enhancing crop production in all constituent entities of the Russian Federation. Along with this, to ensure sustainable development of this industry, it is necessary to address a whole range of conditions and factors. First of all, it is important to improve agricultural awareness, optimize the area of landholdings owned by commodity producers, to increase the economic fertility of soils and the efficiency of the utilization of land resources. In modern conditions, the managerial and organizational levers of horticulture are the development of modern farming systems based on the use of innovative achievements encompassing technical, technological and organizational-economic measures to increase the volumetric indicators of production and improve its quality [5].

The level of development of the agrarian sector evaluated over the past three years suggest that, compared to 2017, the value growth rate of the volume of production in comparable prices in agriculture as a whole in 2019 reached $103.8 \%$, which means that the indicators established by the State program [6], exceeds the target by 1 percentage point (hereinafter - p.p.). Although in 2018 there was a slight fall by $0.2 \%$ in the growth rate of agricultural production. The fulfillment of the planned values of the program is the main indicator of the implementation of the agricultural development program of the country at large, which is provided for by the policy of the government to achieve import substitution of basic food and foodstuffs. The fulfillment indicators and target values of the State program are shown in Table 1.

Table 1. Implementation of the planned values stipulated by the State program [7]

\begin{tabular}{|c|c|c|c|c|c|}
\hline Index & \multirow{2}{*}{$\mathbf{2 0 1 7}$} & $\mathbf{2 0 1 8}$ & \multicolumn{3}{|c|}{$\mathbf{2 0 1 9}$} \\
\cline { 4 - 6 } & & & plan & fact & implemented, \% \\
\hline Agricultural production index in farms of all categories (in comparable prices) by & & & & \multirow{2}{*}{} & \\
$2017 \%$ & 100 & 99.8 & 102.8 & 103.8 & 101 \\
\hline Index of physical volume of capital investments in fixed assets of agriculture by & & & & & \\
$2017, \%$ & 100 & 104.4 & 105.1 & 102 & 97.1 \\
\hline Produced added value in agriculture, billion rubles & 3264 & 3529 & 3852 & 3795 & 98.5 \\
\hline Growth rate of exports of agricultural products by 2017, \% & 100 & 119.3 & 111.1 & 118.4 & 106.6 \\
\hline Crop production index in farms of all categories (in comparable prices) by 2017, \% & 100 & 98.5 & 102.3 & 104.5 & 102.2 \\
\hline Livestock production index in farms of all categories (in comparable prices) by & & & & & \\
$2017, \%$ & 100 & 101.1 & 103.5 & 102.7 & 99.2 \\
\hline Food production index (in comparable prices) by 2017, \% & 100 & 104.9 & 105.9 & 110 & 103.9 \\
\hline Profitability of agricultural enterprises (including subsidies), \% & 12 & 12.5 & 16 & 14.6 & 91.3 \\
\hline
\end{tabular}

The above data indicate that the growth in agricultural production is not accompanied by growing volumes of investment injections. The growth rates are lower than planned, i.e. they lag behind and this is also in the context of ensuring proportional balanced development of all interrelated indicators of the industry's development. This disproportion is exacerbated by a decrease in the value added generated in the production activities of agricultural producers, which amounts to RUB 57 billion or underperformance is $1.5 \%$. This phenomenon raises long-term concerns, threatens with a decrease in the capacity of the production potential of agricultural business entities. Against this background, at first glance, one can be optimistic about the fulfillment of the growth rate of export potential, which is $6.6 \%$, as a source of foreign exchange injections for the development of the rural economy. However, it is necessary to take into account 
here a high share of intermediary enterprises involved in export earnings, which buy products from agricultural producers at average domestic market prices. Due to the lack of expertise in foreign markets and export transactions concluded, the underdeveloped market infrastructure and logistics, agricultural producers on their own cannot hammer out business deals with foreign exporters of food products, they are forced to sell their products through agents. In this case, the agents have a significant part of the export that does not reach the beneficiaries of the agricultural market improvements and does not serve as investment sources for the development of agricultural production [8].

This situation had an effect on the achievements of agricultural producers in terms of the volume of investments in fixed assets, which decreased in 2019 compared to the 2017 indicators by 3.1 percentage points and in terms of growth rates did not reach $2.9 \%$ of the value of the target indicator stipulated by the State program [6]. The reason for this was, first of all, a prohibitive debt burden incurred by the majority of agrarian business entities, an increased difference in the growth rates of prices for goods, services in the servicing sectors of agriculture and for agricultural products. In addition, in recent years, much attention has been paid to the processing of agricultural products and the delivery of foods to consumers in a ready-to-eat form, which requires the reorientation of significant amounts of investment to the sectors involved in the processing of agricultural products and to the development of food industry enterprises [9].

The data in Table 1 also show that the gain in crop production for all categories of producers in 2019 to the level of 2017 amounted to $4.5 \%$, which exceeds the indicative value laid down in the Program by 2.2 percentage points. The natural and climatic conditions of 2019 were most suitable for farmers, contributing to growing and harvesting a large volume of production for the main types of crops, often exceeding the record achievements of recent times in some branches of horticulture.

Along with this, although the growth rates of livestock production increased in 2019 compared to 2017 within $102.7 \%$, the value of the planned indicator remained unfulfilled by 0.8 percentage points, which can be assessed as one of the constraining factors of sustainable growth of agriculture [10]. The reason for this phenomenon was the reduction in production of certain types of livestock products. From the standpoint of strengthening the sustainable balanced growth of all sectors of agriculture, such a ratio of the growth rates of crop and livestock production is extremely undesirable, since the sale of crop production in its original form is always low profitable for business in the domestic agricultural market. Therefore, it is desirable to sell crop production through livestock products by increasing the livestock and increasing productivity, using a growing potential of crop production in the form of grain fodder and fodder crops.

The growing potential for the volume of agricultural production subsequently led to an increase in the food production index in 2019 compared to 2017 by 10 p.p. and exceeded the targets of the State program by $3.9 \%$. The level of profitability of production and economic activities of agricultural organizations, taking into account the amount of state subsidies, increased over the past three years by 2.6 p.p. but did not reach the planned value by $8.7 \%$. The general level of profitability of $14.6 \%$ for modern agricultural organizations is not sufficient to encourage expanded reproduction. The more intensive global transformation of agricultural production is required [10].

Transformation and technical re-equipment of the agrarian sector of the economy, taking into account its starting position and the socio-economic significance of the outcomes and development prospects, requires large investments, the volumes and structure of which are shown in Table 2.

Table 2. Structure of investments in fixed assets in the farming industry by sources of financing [11]

\begin{tabular}{|c|c|c|c|c|}
\hline \multirow[t]{2}{*}{ Index } & \multicolumn{4}{|c|}{ Years } \\
\hline & 2016 & 2017 & 2018 & 2019 \\
\hline $\begin{array}{l}\text { Investments in fixed assets of } \\
\text { the farming industry - total, } \\
\text { billion rubles (in actual prices) }\end{array}$ & 583.9 & 589.0 & 679.7 & 719.0 \\
\hline \multicolumn{5}{|c|}{ Investments in fixed assets, $\%$} \\
\hline All funding sources & 100 & 100 & 100 & 100 \\
\hline including those through: & & & & \\
\hline own funds & 65.7 & 66.0 & 61.7 & 63.4 \\
\hline federal budget & 1.5 & 0.4 & 0.2 & 0.1 \\
\hline $\begin{array}{l}\text { budget of the constituent entities } \\
\text { of the Russian Federation }\end{array}$ & 0.6 & 0.8 & 0.4 & 0.7 \\
\hline $\begin{array}{l}\text { borrowed funds of enterprises, } \\
\text { organizations and other sources }\end{array}$ & 32.2 & 32.8 & 37.7 & 35.8 \\
\hline
\end{tabular}

The table shows that the volume of investments in fixed assets in the farming industry has increased by 135.1 billion rubles over the past four years at actual prices or by $23.1 \%$ in a progressively increasing order. Yet, this process is more and more put onto the shoulders of agricultural producers. The share of the federal budget in the development of fixed capital of the farming industry is only $0.1 \%$, and the share of funds from the budgets of the constituent entities of the Russian Federation is $0.7 \%$. Here, it is also necessary not to dismiss the following distribution of budgetary funds for the renewal of fixed capital. The first part should be spent on updating the fixed capital of the budgetary service, aimed at maintaining the governing bodies responsible for phytosanitary, quality, technical and other control functions in the food chain: maintaining a structure that provides consulting, scientific, informational and other types of services to farming enterprises. Only the second part of the budget funds should be directed to reconstructing the fixed capital of farming enterprises and subdivisions engaged in the direct crop and livestock production. $63.4 \%$ of the fixed capital of agricultural business entities is renewed at their own expense, another $35.8 \%$ - at the expense of borrowed funds from enterprises, organizations and other sources [12]. The share of borrowed funds is routinely increasing, which indicates that farming enterprises find it hard to be involved in expanded 
reproduction on their own. It is known that borrowed funds must be returned with interest. The more borrowed funds are involved in circulation, the more difficult it is to return them. They will expand like a snowball, and in the near future, commodity producers will be forced to withdraw active capital from circulation in order to repay debts and limit funds for further development, which may increase in multiples due to the upcoming digitalization of the rural economy and the automation of production processes. Production facilities are commissioned in all sectors of agriculture [13]. The largest renovation of premises for cattle was made in 201 when 275.1 thousand cattle stalls were put into operation. In other years, the pace of commissioning was approximately the same. In pig breeding, the same situation was observed. This can be due to the fact that following a series of sanctions announced on the part of Western countries, an import substitution program was adopted and the premises the farmers had started to construct were then ready for commissioning in one and a half to two years. With the weak positions of sheep breeding, the pace of construction and commissioning of premises for this industry was increasing. For four years, the rates grew by 3.7 times. Premises for poultry farming were being built at an accelerated pace. For the egg direction, the rate increased by 1.5 times, for the meat direction - by4.5 times. Poultry farming was developing at a high rate not only to meet domestic needs, but also to supply poultry products for export.

Ultimately, in the commodity export structure developed in the Russian Federation, the share of food products and agricultural raw materials in 2019 amounted to $6 \%$. The total amount of food turnover of the Russian Federation with foreign countries remained at the same level in 2019, as compared to 2018, with an increase in imports by $0.7 \%$ and a decrease in exports by $0.7 \%$ (Table 3 ).

Table 3. Food turnover of the Russian Federation with foreign countries, USD million [14]

\begin{tabular}{|c|c|c|c|c|}
\hline \multirow{2}{*}{ Index } & \multirow{2}{*}{$\mathbf{2 0 1 8}$} & \multirow{2}{*}{$\mathbf{2 0 1 9}$} & \multicolumn{2}{|c|}{ Growth rate } \\
\cline { 4 - 5 } & & & $\mathbf{\%}$ & $\boldsymbol{+} /-$ \\
\hline Turnover & 55559 & 55560 & 100 & 1 \\
\hline Import & 29757 & 29951 & 100.7 & 194 \\
\hline Export & 25802 & 25609 & 99.3 & -193 \\
\hline Trade balance & -3955 & -4342 & 109.8 & -387 \\
\hline
\end{tabular}

In order to ensure sustainable development of the agricultural business in the Russian Federation, the national farming industry is tasked to increase the export of products and foodstuffs to $\$ 45$ billion by 2025 , which is a fundamental position in the development and implementation of the State program and its subprograms. This position is due to the fact that the results of the development of the national economy directly depend on foreign economic activity of agricultural agents to increase the export of food and agricultural raw materials. In this regard, improving the activities of agricultural business entities to increase exports is recognized as one of the priorities. The reason for this is that the export potential and active foreign economic activity of agricultural business entities act as a catalyst in regulating the balance and equilibrium in the promotion of international trade in the country as a whole.

\section{Conclusions}

As a follow-up to sanctions against Russia by Western European countries and the United States, agriculture and the processing industry were tasked with providing the population with foods of its own production at prices affordable for the majority of consumers. As in all cases of history, Russian agriculture and the farming industry got out of this situation with dignity. In conditions of limited material, technical and labor resources, in a short period of time they reached the level of self-sufficiency in basic foodstuffs. According to the consolidated reporting on the performance of agricultural organizations that received government support in 2019, profitability (including subsidies) was $14.6 \%$, which was 1.4 p.p. below the target $(16 \%)$, but higher than the level of 2018 by 2.1 p.p. (12.5\%). In 2019, in the agricultural business sector, before-tax income (including subsidies) was received in the amount of 377.5 billion rubles, which was $20.5 \%$ higher than the level of 2018. Moreover, the share of profitable farms in the total number of agricultural business entities amounted to $87.2 \%$ (by 4.2 p.p. higher than the previous year), though their total number was reduced. Disregarding subsidies, the profitability was $9.9 \%$ against $6.3 \%$ in 2018. The profitability level was not high. Given the level of annual inflation, it turned out to be very low. Such a level of return on investment does not allow agricultural organizations, being dynamically developing subjects of agricultural business, to be involved in innovative and investment activities to develop entrepreneurship in rural areas. In addition, the agrarian business plays a huge role as a socially responsible business that has taken on the burden of infrastructure development of rural areas in order to create favorable living conditions for the rural population, increase the attractiveness and content of the rural lifestyle and agricultural labor.

\section{References}

1. D.F. Khafizov, Features of the current stage of development of a mixed economy, Bull. of the Kazan State Agrar. Univ., 3, 157-161 (2018)

2. D.I. Fayzrakhmanov, Current state and problems of agricultural development in the context of Russian membership in the WTO, Bull. of Kazan State Agrar. Univ., 2, 58-64 (2013)

3. F.N. Avkhadiev, Increasing the sustainability of grain production (based on the materials of the Republic of Tatarstan), Bull. of Kazan State Agrar. Univ., 4, 104-108 (2016)

4. F. Mukhametgaliev, L. Sitdikova, F. Avkhadiev et al., Problems of regional grain market development, 
BIO Web of Conf., 17 (2020), Retrieved from: https:doi.org10.1051bioconf20201700059

5. L.V. Mikhailova, Methodological features of planning the development of small businesses in agriculture, Competitiv. in the global world: econ., sci., technol., 7(Part 4), 100-103 (2017)

6. State program for the development of agriculture and regulation of markets for agricultural products, raw materials and food for 2013-2020 (Moscow, 2012), $204 \mathrm{p}$.

7. On the progress and results of the implementation of the state program in 2019 for the development of agriculture and regulation of markets for agricultural products, raw materials and food, National report, Retrieved from: https mcx.gov.ru upload iblock 98a 98af7d467b718d07d5f138d4fe96eb6d.pdf2019_992_June.pdf

8. F.N. Avkhadiev, Main directions of technical modernization of agriculture in the Republic of Tatarstan, Rural mach. and equip., 4, 46-48 (2017)
9. F.N. Mukhametgaliev, L.F. Sitdikova, F.F. Mukhametgalieva et al., Trends in the formation of the current agrifood policy of Russia, Stud. on Russ. Econ. Developm., 30(2), 162-165 (2019)

10. Federal State Statistics Service of the Russian Federation, Retrieved from: http:www.gks.ru

11. Agriculture of Russia (FGBNU "Rosinformagrotech", Moscow, 2020), p. 53

12. D.I. Fayzrakhmanov, O.V. Kirillova, The main directions of support for the Russian agro-industrial complex in the context of the WTO, Bull. of Kazan State Agrar. Univ., 4, 28-30 (2015)

13. Main trends in export traffic in the first half of the 2019-2020 season and forecast for the second half of the season, Retrieved from: https:www.rusagrotrans.ruupload\% 2020.pd

14. D.F. Khafizov, Issues of development of small businesses and cooperation in rural areas, Bull. of Kazan State Agrar. Univ., 1, 138-144 (2019) 